\title{
Effect of soil properties on the dynamic response of simply-supported bridges under railway traffic through coupled boundary element-finite element analyses
}

\author{
M.D. Martínez-Rodrigo ${ }^{\mathrm{a}, *}$, P. Galvín ${ }^{\mathrm{b}}$, A. Doménech ${ }^{\mathrm{a}}$, A. Romero ${ }^{\mathrm{b}}$ \\ ${ }^{a}$ Universitat Jaume I, Department of Mechanical Engineering and Construction, Avda. Sos Baynat s/n, 12071 Castellón, Spain \\ ${ }^{b}$ Universidad de Sevilla, Escuela Técnica Superior de Ingeniería, Camino de los Descubrimientos s/n, 41092 Sevilla, Spain
}

\begin{abstract}
Railway induced vibrations on short-to-medium span simply-supported (SS) bridges is addressed in this contribution. Such structures may experience high levels of vertical acceleration at the platform, leading to adverse consequences such as a premature degradation of the ballast layer and passenger discomfort. In the present study, the evolution of the bridge dynamic response when soil-structure interaction (SSI) is taken into account is investigated. To this end a coupled three-dimensional (3D) Boundary Element-Finite Element model (BEM-FEM) formulated in the time domain is implemented to reproduce the soil and structural behaviour, respectively. First, a set of soil-bridge systems of interest is defined, covering a wide range of lengths and natural frequencies for the structures, and an interval of expectable elastic properties and damping levels for the soil. Then, different types of analyses are performed on the soil-bridge systems extracting conclusions regarding the effect of including SSI in numerical models for predicting the bridge behaviour under railway traffic. In particular natural frequencies and modal damping levels are identified, and the structure amplification after the passage of a moving load in free vibration is investigated. Conclusions regarding how resonance and cancellation conditions may be affected by soil properties are extracted. Finally, the dynamic response of a real bridge, belonging to the Spanish railway network, is evaluated under the circulation of trains that induce second and third resonances of the bridge fundamental mode. The effect of the soil flexibility, soil material damping and the bridge resonance order are evaluated. Conclusions regarding the appropriateness of the results provided by common models which do not include SSI effects are extracted.
\end{abstract}

Keywords: Railway bridges, soil-structure interaction, resonance, cancellation, moving loads, BEM-FEM coupled models

\section{Introduction}

The development of modern, efficient and operational transport systems is essential for a sustainable economic development. In this context the construction of new High-Speed railway lines and upgrading of conventional lines for higher operating speeds, has become a trend in Asian and European countries in the last decades. Railway infrastructures and, in particular, railway bridges, are expected to exhibit an adequate performance under these new traffic requirements guaranteeing traffic safety, passengers comfort, structural integrity and acceptable environmental conditions in terms of sound and vibration transmitted amplitudes.

The level of vibrations induced on bridges due to the circulation of railway convoys has become an issue of concern among the scientific and engineering community, due to the periodic nature of the vehicles axles and the operating speeds approaching and exceeding $300 \mathrm{~km} / \mathrm{h}$ in many lines. The periodic nature of the axle transmitted forces may excite important transverse vibration levels in the structures, particularly under resonant conditions [1, 2]. Especially critical in this regard are shortto-medium span bridges composed by SS decks with usually

\footnotetext{
${ }^{*}$ Corresponding author. Tel.: +34 964387473; fax: +34964728106

Email address: mrodrigo@uji.es (M.D. Martínez-Rodrigo)
}

associated low masses. This problem aggravates for low structural damping levels, typical in the aforementioned constructions [1]. Figure 1 shows two examples of such structures, belonging to the Spanish railway network, with decks composed by concrete slabs resting on series of pre-stressed concrete girders. Even though this typology is not common in High-Speed lines of new construction, due to its poor dynamic performance [3], these beam-type bridges do exist in former conventional lines upgraded for High-Speed.

Resonance in railway bridges may lead to adverse consequences such as ballast destabilization, passenger discomfort, a general degradation of the track and a raise in the maintenance costs of the line $[1,4]$. For this reason, according to standards, the maximum deck acceleration must be checked at the Serviceability Limit State for the prevention of track instability, and regarded as a traffic safety requirement [5].

Resonance takes place when the excitation period of the axles, $i$. $e$., the ratio between a characteristic, or many times repeated, distance and the train speed is a multiple of one natural period of the structure. When this occurs, the free vibration oscillations induced by every load accumulate, and the transverse response of the bridge progressively increases, leading to a substantial amplification if the number of axles is sufficient. In short to medium span bridges with nowadays maximum train speeds, the characteristic distance associated with detrimental 

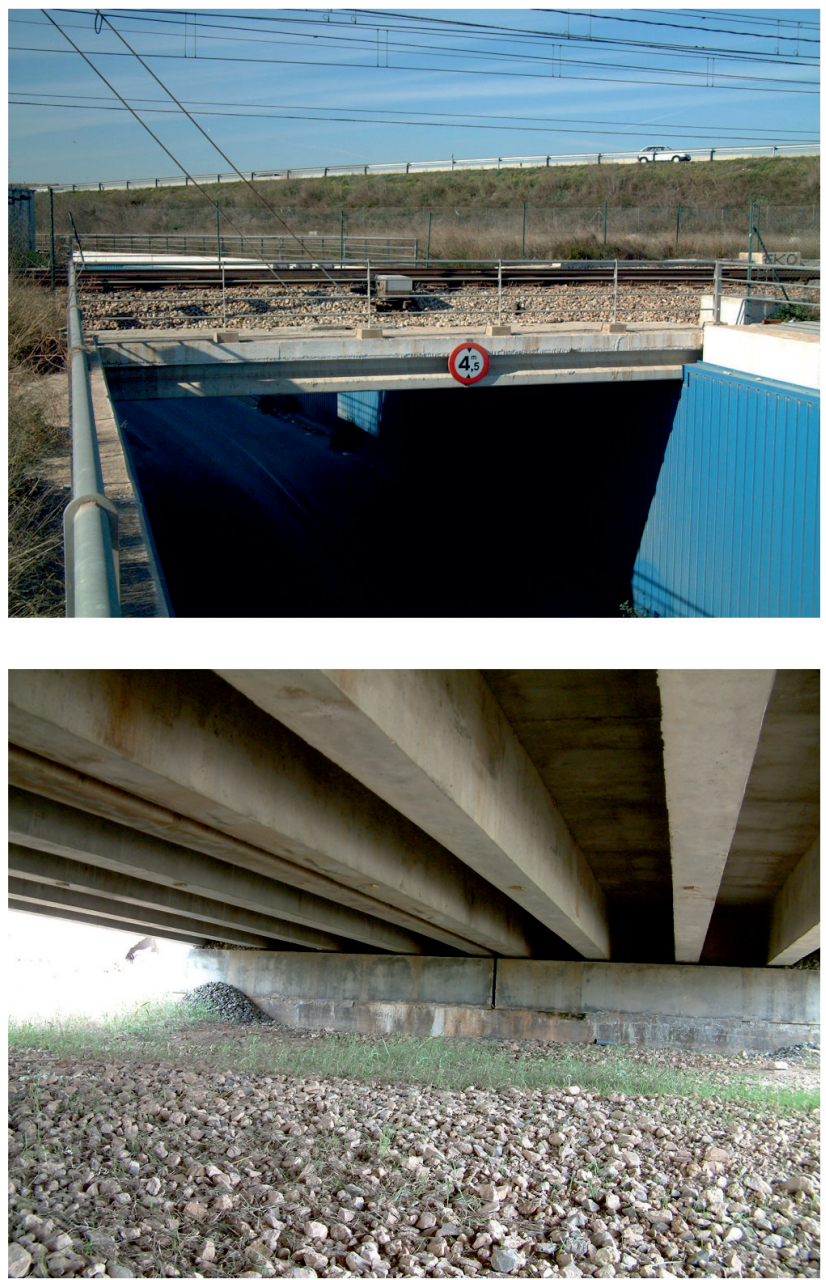

Figure 1: Railway bridges in Spanish lines composed by simply-supported bays of short-to-medium span

levels of transverse accelerations due to resonance usually corresponds to the length of the passengers' coaches. Therefore, the dynamic amplification of beams or bridges at resonance depends both on the periodicity of the loads and on the amplitude of the free vibrations left by every single load. Under ideal SS conditions and in the absence of damping, the amplification of the free vibrations left by every load depends on the ratio between the structural periods and the travelling time of the load. As indicated in [6], depending on this ratio the beam may experience substantial levels of free vibrations (maximum free vibrations) or these may practically cancel (cancellation of free vibrations).

If the limits on the bridge deck acceleration cannot be met in an existing structure, strengthening measures may be applied in order to modify its dynamic properties and, consequently, its dynamic behaviour [7]. Passive control techniques could also provide cost-effective solutions increasing the overall damping levels of the structure and reducing the deck vibrational response at resonance [8]. In either case of new or existing structures, it is essential to develop accurate numerical models, able to realistically predict the vibration levels for the expected traf- fic conditions in order to make the best decision in the design stage or when a line is upgraded for higher operating speeds. According to some authors [9], the choice of boundary conditions for dynamic analyses appears to constitute a group of very sensitive parameters which have a considerable influence on the dynamic response of certain bridge types.

The phenomena of resonance and cancellation experienced by beams or bridges under the circulation of moving loads has been studied by several researchers [6, 10-17]. Nevertheless in the previous works, soil-structure interaction is always disregarded and classical boundary conditions are assumed for the bridge deck. According to some authors, in certain soil environments an increase in the fundamental natural periods of moderately flexible structures due to SSI may have a detrimental effect on the structural behaviour [18]. The work presented herein arises in this context.

Only a few authors have investigated the dynamic response of beams or bridges and, in particular, the conditions of resonance and cancellation phenomena taking into account the wave propagation in the soil. Lu et al. [19] prove numerically the occurrence of resonance and cancellation in a periodic viaduct subject to moving loads considering pile-soilstructure interaction. Wu and Yang [20] apply a semi-analytical approach to analyse ground vibrations induced by trains moving over elevated bridges. The authors use impedance functions to represent the foundation-soil interaction and an elastic half space model for the soil wave propagation problem. In [21] and [22] the authors investigate ground vibrations induced by High-Speed trains crossing continuous girder bridges and rigid-frame viaducts, respectively. In both contributions the ground response is calculated by applying reaction forces on a 3D FEM with artificial viscous boundaries. Takemiya and Bian [23] investigate numerically the waves generated in the soil near a Japanese Shinkansen multi-span viaduct. The authors also present field tests measurements on the foundations and in the ground far field, showing frequency contents related to train axle distances and structure natural periods. In [9] ÜlkerKaustell et al. present a qualitative analysis of the dynamic SSI phenomenon on a portal frame railway bridge based on dynamic stiffness functions. The authors conclude that the contribution of the coupled soil-bridge system to the modal damping ratios is substantial, especially for the lower range of the soil elastic modulus.

Most of the previous works focus on the level of vibrations transmitted through the soil along the track, rather than on the bridge behaviour itself. In the opinion of the authors of this contribution, there is a need to investigate how soil properties, in terms of flexibility and material damping, may affect the dynamic response of short SS bridges susceptible to experience excessive accelerations at the deck level. If this kind of analysis is performed with generality, $i$. $e$., considering expectable ranges of variation of structural and soil properties, interesting conclusions could be extracted regarding the appropriateness of the numerical models usually used by engineers when it comes to assess the performance of new structures, or that of existing structures subjected to more demanding operating conditions. In this study the authors complete the investigation initiated 
in reference [24], extending the analysis to several soil types with different levels of material damping, and particularizing the conclusions extracted to the case of a real structure.

In what follows a comprehensive ensemble of soil-bridge systems is defined covering typical lengths and structural typologies of short to medium span SS railway bridges, and a wide range of variation of soil flexibilities and material damping values. A sensitivity analysis is conducted on this ensemble and the evolution of the bridges natural frequencies and structural damping levels is evaluated with the properties of the soil. The amplification of the bridge dynamic response in free vibration under a single moving load (SML) is then presented, and, based on this analysis, conclusions regarding the evolution of the resonant and cancellation phenomena induced by multiple moving loads (MML) with soil properties is discussed. Finally, the dynamic response of a real bridge belonging to the Spanish railway network is analysed under railway traffic. The evolution of the structure response under different order resonant conditions and under not resonant conditions with the flexibility and damping of the surrounding soil is evaluated. Finally conclusions are extracted regarding the adequacy of numerical models that disregard SSI effects.

\section{Formulation and approach adopted}

\subsection{Approach of the investigation}

The numerical model implemented for the investigation has been previously presented in [24] and its main features are summarized herein. It is a fully coupled 3D BEM-FEM model integrated in the time domain. The SSI problem is analysed by domain decomposition in the soil and structure sub-domains, represented with the BEM and the FEM, respectively. BEMFEM coupling is performed directly. A scheme showing the main parts of the model is represented in Figure 2.

The main features of the BEM-FEM model are:

- A beam FEM is used to represent the deck flexural behaviour under moving loads, therefore assuming that the maximum transverse response of the structure is mainly governed by its longitudinal bending deformation. This decission is justified by the facts that: (i) according to previous studies [6, 25], short to medium span SS railway decks are expected to exhibit maximum vertical acceleration levels at mid-span; (ii) in reinforced concrete slabs or prestressed concrete girder decks, usual typologies for the range of lengths under consideration, resonances of the first torsion mode are usually not determinant in the assessment of the Ultimate Limit State of vertical acceleration [25]; (iii) the objetive of this investigation is to evaluate SSI effects on the main resonant problem that railway decks may experience under railway traffic.

- The beam bridges are idealised as Bernoulli-Euler (BE) beams in a finite element context. The beam is discretized using two node beam elements with tension, compression, torsion (not excited considering the 2D nature of the applied loads), and bending capabilities. The choice of the

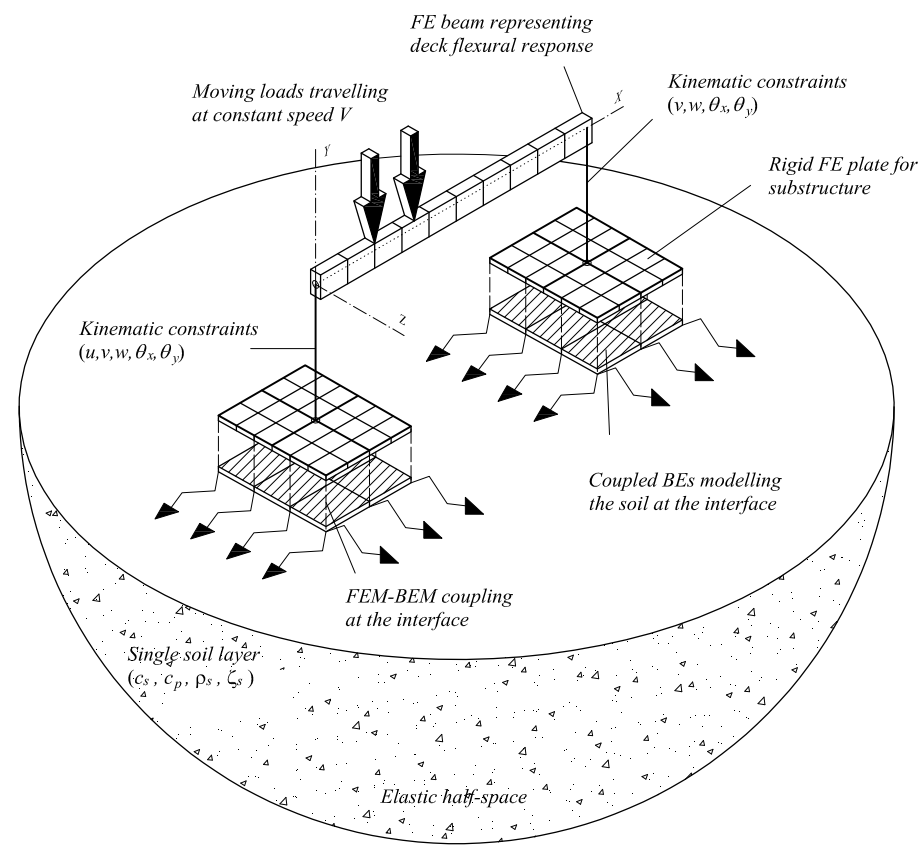

Figure 2: Schematic representation of the 3D BEM-FEM coupled model

Bernoulli-Euler theory is well suited for the analysis of railway bridges in this study due to the slenderness ratios of typical railway decks $[1,26]$. Moreover, the frequency range of interest in the study is low (under $30 \mathrm{~Hz}$ ) and mismatches between Bernoulli-Euler and Timoshenko beams are expected to be relevant above $50 \mathrm{~Hz}$ [27].

- The influence of the track and the ballast, which can also affect the dynamic behaviour of the bridge [28-32], has been taken into account only by means of the associated dead masses. A detailed vehicle idealisation, that would cause a reduction in the vibration levels of the bridge $[33,34]$ at resonance and of the ground [35], is also disregarded, and a moving load model has been used during the investigation. These simplifications, consistent with common design practices, have also been adopted in prior investigations of the resonance and cancellation phenomena in railway bridges $[6,11,16,17]$, and it has been considered convenient in a first approach to the problem. Additionally, as it will be shown in what follows, vehiclebridge interaction and SSI will both lead to a reduction of the deck acceleration at resonance. On the authors opinion it is essential to separate both effects in order to capture the effects caused by the soil separately and be able to extract conclusions in this regard.

- The railway excitation is introduced as a sequence of moving loads travelling at constant speed, therefore neglecting vehicle-structure interaction effects. The gradual nature of the wheel loads application process close to the abutments due to the distributive effect of rails, sleepers and ballast must be simulated in order to avoid unrealistic high frequency modal contributions. To this end, a load distribu- 
tion function based on the Zimmerman-Timoshenko solution for an infinite beam on Winkler foundation, is applied to the axle load modulus in the abutments proximities. Details of the formulation may be found in [8].

- The beam end sections are connected through kinematic constraints to two rigid plates representing the lower surface of shallow foundations at the abutments. These plates are coupled to the boundary elements simulating the interaction with the soil. With this simple idealization, the essence of the wave propagation problem is isolated from the foundations geometry, and its influence is evaluated considering only the bridge vibration response [36].

- Regarding the soil treatment, a homogeneous soil with constant properties is admitted. The Green's function for an elastic half-space is used as the fundamental solution for displacements and tractions in the BEM [37]. Therefore, the boundary element discretisation is limited to the interface between the soil and the plates. The soil is discretised using nine node rectangular quadratic boundary elements.

- Coupling of the BEM and FEM equations is carried out by imposing equilibrium and compatibility conditions at the soil-structure interface. Both systems of equations are assembled into a single system, together with the equilibrium and compatibility conditions [38].

The described model is implemented in the SSIFiBo toolbox for MATLAB previously developed by coauthors of this contribution Galvín and Romero [39-41]. The FEM module of the toolbox does not include any pre-processor. Instead, a gateway for commercial software allows importing directly the structure model. Using this model, SSI effects on the transverse response of beams traversed by moving loads at constant speeds are studied by means of the following complementary steps:

1. First (section 3.1), a preliminary analysis is presented based on the frequency response function (FRF) of a soilbridge system under impulse excitation, with the aim of anticipating the influence of the soil properties on the bridges response in the frequency domain. This issue is related with the relative values of the Rayleigh and beam bending wavelengths.

2. Second (section 3.2), the variation of modal parameters (fundamental frequency and modal damping) of the bridges under study considering SSI is analysed. It should be remarked that, as explained in section 2.3, the bridges and soil properties have been selected covering a wide range of realistic combinations in the design of short SS railway bridges.

3. Third (section 3.3), the maximum response of the structures under the circulation of a single moving load in terms of the uniform speed is presented, and the conditions for maximum response and cancellation during the free vibration phase (once the load has left the structure) are shown.
General conclusions regarding the influence that soil properties may have on resonant speeds and associated amplitudes are extracted from these results.

4. Finally (section 4), the dynamic response of a real SS railway bridge belonging to the Spanish railway network is analysed under the circulation of a train of moving loads exciting two relevant resonant situations in the range of speeds considered. The influence of the soil flexibility and material damping is investigated when the bridge undergoes resonances of different order and at non-resonant conditions.

\subsection{BEM-FEM mathematical formulation}

The BEM is based on a time marching procedure to obtain the time variation of the boundary unknowns; $i$. $e$., displacements and tractions. The $k-t h$ component for displacements and tractions over the boundary is approximated from the nodal values $j$ at each time step $m, u_{k}^{m j}$ and $p_{k}^{m j}$, using the space interpolation functions $\phi^{j}(r)$ and $\psi^{j}(r)$, for tractions and displacements, respectively. After interpolating the boundary variables, the integral representation of the displacement $u$ at a point $i$ on the boundary becomes [40]:

$$
\begin{aligned}
c_{l k}^{i} u_{k}^{i}\left(\mathbf{x}^{i}, t\right) & =\sum_{m=1}^{n} \sum_{j=1}^{Q}\left\{\left[\int_{\Gamma_{j}} U_{l k}^{n m} \psi^{j} d \Gamma\right] p_{k}^{m j}\right. \\
& \left.-\left[\int_{\Gamma_{j}} P_{l k}^{n m} d \tau \phi^{j} d \Gamma\right] u_{k}^{m j}\right\}
\end{aligned}
$$

where $Q$ is the total number of boundary nodes and $\Gamma_{j}$ represents the elements to which node $j$ belongs. Time kernels $U_{l k}^{n m}$ and $P_{l k}^{n m}$ are respectively computed through the fundamental solution for displacements and tractions due to a point load acting at $\mathbf{x}^{i}$ in the $l$ direction. These kernels are analytically integrated by parts using constant and linear piecewise time interpolation functions for tractions and displacements [37], respectively. Eq. (1) may be written in a more compact form as:

$$
c_{l k}^{i} u_{k}^{n i}=\sum_{m=1}^{n} \sum_{j=1}^{Q}\left[G_{l k}^{n m i j} p_{k}^{m j}-\widehat{H}_{l k}^{n m i j} u_{k}^{m j}\right]
$$

Once the integral-free term $c_{l k}^{i}$ is included in the system matrix, the integral representation for point $i$ at time $t=n \Delta t$ becomes:

$$
\mathbf{H}^{n n} \mathbf{u}^{n}=\mathbf{G}^{n n} \mathbf{p}^{n}+\sum_{m=1}^{n-1}\left[\mathbf{G}^{n m} \mathbf{p}^{m}-\mathbf{H}^{n m} \mathbf{u}^{m}\right]
$$

where $H_{l k}^{n m i j}$ collects for $c_{l k}^{i}$ when $i=j$ and $n=m$.

The FEM equation at time step $n$ is defined as [42]:

$$
\mathbf{M} \ddot{\mathbf{u}}^{n}+\mathbf{C} \dot{\mathbf{u}}^{n}+\mathbf{K} \mathbf{u}^{n}=\mathbf{f}^{n}
$$

where $\mathbf{M}, \mathbf{C}$ y $\mathbf{K}$ are the mass, damping, and stiffness matrices, respectively. $\mathbf{u}^{n}, \dot{\mathbf{u}}^{n} \mathrm{y} \ddot{\mathbf{u}}^{n}$ represent nodal displacement, velocity, and acceleration vectors, respectively, and $\mathbf{f}^{n}$ is the load vector 
including the effect of the constant moving load at each timestep. Equation 4 is solved using an implicit time integration GN22 Newmark method $[42,43]$. An equivalent dynamic stiffness matrix is defined:

$$
\mathbf{D u} \mathbf{u}^{n}=\mathbf{f}^{n}+\mathbf{f}^{n-1}
$$

Coupling of BEM and FEM equations (Eqs. (3) and (5)) is carried out by imposing equilibrium and compatibility conditions at the soil-structure interface. Both systems of equations are assembled into a single global system, together with the equilibrium and compatibility equations [44].

As the plate foundations have been defined as rigid bodies in a first approach through kinematic constraints, the BEM Eq. (3) is expressed in terms of the kinematic constraint matrix $\mathbf{L}$ relating the displacements and tractions of the central point of the plate, $\mathbf{u}_{0}$ and $\mathbf{p}_{0}$, respectively, with any other point for each foundation:

$$
\mathbf{H}^{n n} \mathbf{L} \mathbf{u}_{0}^{n}=\mathbf{G}^{n n} \mathbf{L} \mathbf{T} \mathbf{p}_{0}^{n}+\sum_{m=1}^{n-1}\left[\mathbf{G}^{n m} \mathbf{L} \mathbf{T} \mathbf{p}_{0}^{m}-\mathbf{H}^{n m} \mathbf{L} \mathbf{u}_{0}^{m}\right]
$$

where equilibrium of forces at the interface $\Gamma$ is fulfilled integrating nodal tractions according to the element shape function matrix $\mathbf{N}$ :

$$
\mathbf{f}=\int_{\Gamma} \mathbf{N}^{T} \mathbf{p} \mathbf{N} d \Gamma=\mathbf{T} \mathbf{p}
$$

The time step $\Delta t$ for the analysis is set sufficiently small to properly integrate the structure dynamic response and load excitation. This may be expressed as:

$$
\Delta t=\min \left(\frac{2 \pi}{\omega_{1} k_{\omega}}, \frac{L}{V k_{v}}\right)
$$

where $\omega_{1}$ corresponds to the fundamental frequency of the beam, $L$ is the beam length, and $V$ the load speed. Parameters $k_{\omega}$ and $k_{v}$ define time discretizations for the structure fundamental period and the load passage time, respectively.

The chosen time step determines the spatial boundary element discretization according to the stability parameter $\beta=$ $c_{s} \Delta t / \Delta l$, where $\Delta l$ is the distance between two nodes of a boundary element, and $c_{s}$ is the shear wave propagation velocity in the soil. In this work, a stability parameter $\beta=0.5$ has been considered.

The finite element representation is determined by the bridge bending wavelength discretization. Minimum wavelength is defined by the maximum frequency range and the phase bending wave propagation velocity in the fundamental mode $c_{b 1}=$ $\sqrt[4]{\omega_{1}^{2} E I_{z} / m_{b}}$, where $E I_{z}$ is the beam cross-section bending stiffness and $m_{b}$ is the beam mass per unit length. This work considers 20 elements for the minimum wavelength.

\subsection{Definition of an ensemble of soil-bridge systems}

In this section the ensemble of soil-bridge systems investigated in the sensitivity analysis included in section 3 is presented.
Bridge beam models of lengths ranging from 12.5 to $25 \mathrm{~m}$ in increments of length of $2.5 \mathrm{~m}$ are considered, covering the typical span lengths susceptible to experience high deck vertical accelerations under resonant conditions. The range of fundamental frequencies realistic for each span is selected from the band prescribed by Eurocode 1 [5] for the application of simplified methods (see Figure 3). Therefore, the vast majority of existing and potential SS bridges fundamental frequencies are expected to fall within these limits. Three evenly-spaced sample values between $0 \%$ and $70 \%$ of Eurocode 1 upper frequency limit have been analysed. These frequencies are referred to as $f_{1,000}, f_{1,035}$ and $f_{1,070}$ in what follows. As can be extracted from the studies presented in [33], the majority of railway bridges for conventional and High-Speed lines fall within the selected range.

In a first approach, a single value of mass per unit length is assigned to each beam, in particular $m_{b}=L(m) \cdot 1000 \mathrm{~kg} / \mathrm{m}^{2}$. The mass of the structure will affect the level of vertical acceleration at resonance, but it has not been selected as a parameter for the sensitivity study as it does not govern the maximum free vibration and cancellation conditions in the absence of SSI effects [6]. Structural damping is not assigned to the beams in section 3 in order to isolate the effects of SSI on the modal parameters of the bridges under study. Regarding the substructure, identical $5 \mathrm{~m} \times 5 \mathrm{~m}$ foundation plates are considered in all the cases to represent the soil-substructure interaction surface.

As per the soil properties, three homogeneous soil types are defined with flexibilities covering the AASHTO classification [45]. In particular shear $(s)$ and dilatation $(p)$ wave velocities of $c_{s}=\{150,220,365\} \mathrm{m} / \mathrm{s}$ and $c_{p}=2 c_{s}$ are considered, admitting a Poisson's ratio $v=1 / 3$ for the soil. Soil density has been set equal to $1800 \mathrm{~kg} / \mathrm{m}^{3}$ in all the cases. Soil material damping levels of $\zeta_{s}=\{0,2.5,5\} \%$ are considered for each shear wave velocity. Therefore 180 BEM-FEM models are evaluated in the following sections ( 18 bridges $\times 9$ soil types plus 18 bridges with infinitely rigid soil conditions).

\section{Sensitivity analysis}

\subsection{SSI effect on the bridges behaviour in the frequency do- main. Preliminary analysis}

In order to get some insight regarding how SSI may affect the bridges dynamic response depending on the frequency range, a preliminary analysis is included in this subsection. First, beams and soil wavelengths are computed and represented in order to estimate the frequency range in which the interaction between the structure and the soil could be appreciable. Second, the impulse response of a particular beam is presented and the effect of the soil flexibility and damping are shown in the frequency domain.

Figure 4 represents the Rayleigh wavelength of the soil $\lambda_{R}=$ $c_{R} / f$ and the beam bending wavelength $\lambda_{b}=c_{b} / f$ in terms of the frequency $f . c_{R}$ stands for the Rayleigh wave propagation velocity in the soil, approximated as in [46], and $c_{b}$ for the beam bending wave propagation velocity: 


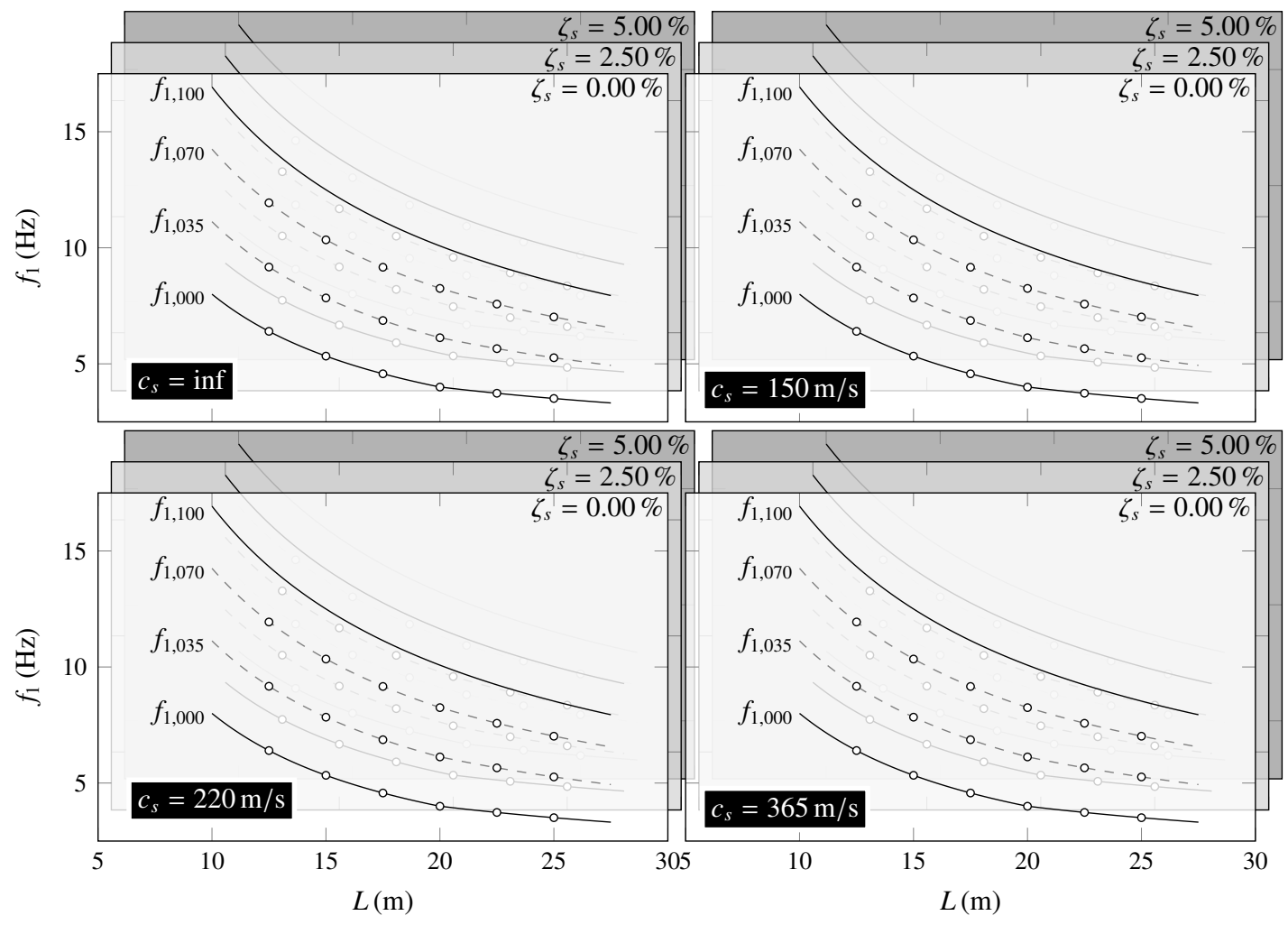

Figure 3: Ensemble of soil-bridge systems under study. $\circ$ Frequency and span length of analysed bridges for particular soil properties $\left(c_{s}, \zeta_{s}\right)$

$$
c_{R}=\frac{0.87+1.12 v}{1+v} c_{s} \quad c_{b}=\sqrt[4]{\omega^{2} E I_{z} / m_{b}}
$$

Both wavelengths have been normalised with respect to the beam wavelength in its fundamental mode for SS conditions $\left(\lambda_{1, s s}=2 L\right)$.

In Figure 4 each graph corresponds to a set of bridges with natural frequencies in the SS case corresponding to levels $f_{1,000}, f_{1,035}, f_{1,070}$ and $f_{1,100}$ in the Eurocode frequency band. $f_{1,100}$ is considered only in this subsection for comparison purposes, as it does not represent common structures of the typologies of interest. In each plot, different curves associated to the same soil type (same gray colour traces) correspond to different span lengths $L=12.5 \mathrm{~m}$ to $L=25 \mathrm{~m}$. Moreover, in the horizontal axis the frequency has been normalised by the fundamental frequency of the SS beam $\left(f / f_{1, s s}\right)$. This normalisation allows to represent all the beams with a single curve given that $\lambda_{b} / \lambda_{1, s s}=\left(f^{2} / f_{1, s s}^{2}\right)^{0.25}$. Two frequency regions may be distinguished for each soil-beam system: (i) a region where the Rayleigh wavelength of the soil is higher than the beam bending wavelength (low frequency range); and (ii) a region where the Rayleigh wavelength of the soil is lower than the wavelength of the beam. The cut-off frequency between both regions may be easily obtained equating both wavelengths $\left(\lambda_{R}=\lambda_{b}\right)$, entailing that $c_{R}=c_{b}$.

Notice that the beam bending wavelength starts to exceed the soil Rayleigh wavelength at a frequency that increases with the soil stiffness and the beam fundamental period. It should be therefore expected SSI to be more perceptible at low frequen- cies on the bridge response in the case of more flexible soils (lower values of $c_{s}$ ) and of beams with higher fundamental frequencies. Moreover, higher modal contributions of the beams should be more affected by SSI effects than the response associated to the fundamental mode.

As an example, Figure 5 shows the frequency response function at $L / 4$ for a bridge span $L=15 \mathrm{~m}$, considering four bridge frequencies covering the complete Eurocode range for that particular length, and different soil conditions (wave propagation velocities and damping ratios). The FRF is computed loading the structure with an impulsive force acting on the same section. The FRF shows peaks at the frequencies corresponding to the first three bending modes of the bridge. The bridge frequencies and the peaks amplitudes move toward lower values as the soil becomes softer, and SSI effects become more important. Also, bridges with higher natural frequencies are most affected by SSI. Moreover, it can be concluded from this analysis that the influence of the soil material damping is almost imperceptible at the fundamental frequency of the structure and it is much more noticeable in the frequency range above the aforementioned cut-off frequency.

In the following sections modal properties of the bridge catalogue under study are identified, and SSI effects on the conditions for maximum free vibration and cancellation of the bridges under a SML are evaluated.

\subsection{Identification of modal parameters}

In view of the results of the previous section and following the approach in [24], a parameter $\kappa=E I_{z} \pi^{3} /\left(K_{v} L^{3}\right)$ is defined 


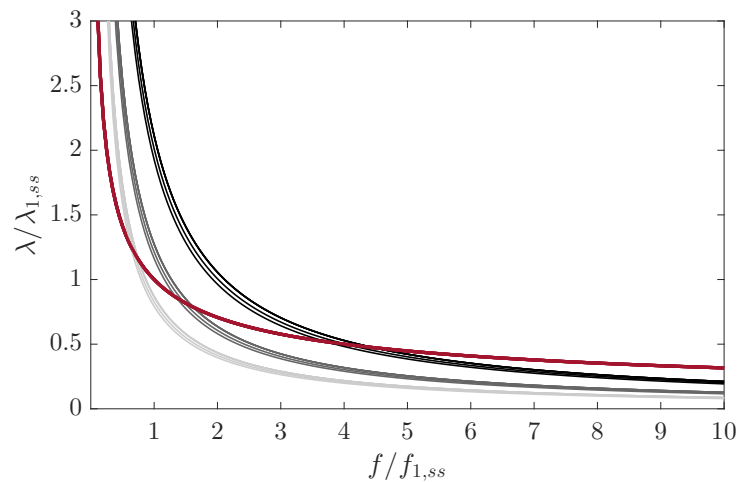

(a) $f_{1,000}$

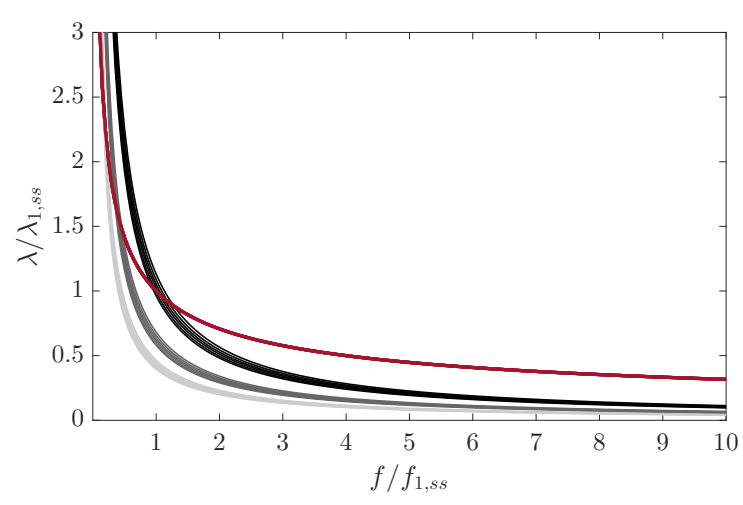

(c) $f_{1,070}$

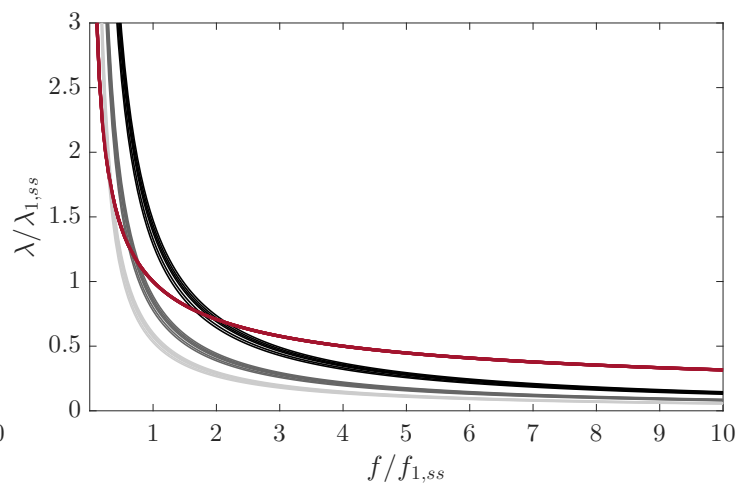

(b) $f_{1,035}$

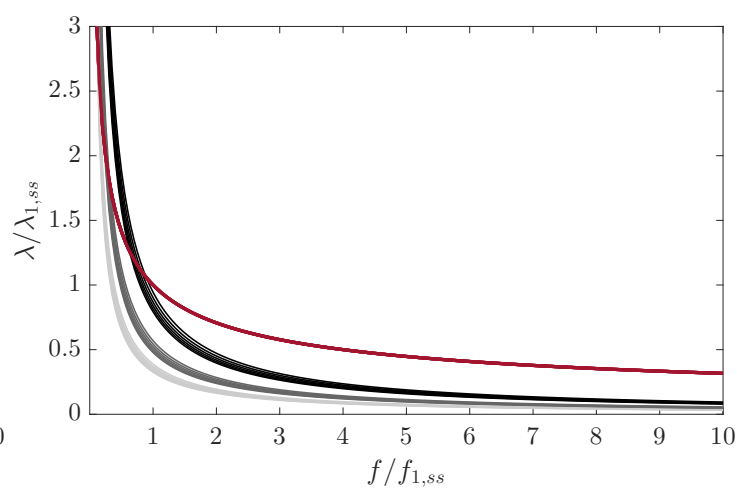

(d) $f_{1,100}$

Figure 4: Rayleigh wavelength $\left(\lambda_{R} / \lambda_{1, s s}\right)$ for different bridge spans (12.5 to $\left.25 \mathrm{~m}\right)$ and soil properties: $c_{s}=150 \mathrm{~m} / \mathrm{s}, \longrightarrow c_{s}=220 \mathrm{~m} / \mathrm{s}$ and $-c_{s}=365 \mathrm{~m} / \mathrm{s}$. Beam bending wavelength $\left(\lambda_{b} / \lambda_{1, s s}\right)$

as the ratio of the flexural rigidity of the bridges to the vertical stiffness of the soil-foundation supports under static loading, $K_{v}$. In Figure 6 the values of $\kappa$ for the soil-bridge systems under study are represented (notice that soil material damping does not affect this parameter). $\kappa=0$ corresponds therefore to an infinitely rigid soil.

The natural frequency and modal damping associated to the fundamental mode are obtained from the beam response subjected to an impulse load for the complete ensemble of bridges under study (108 BEM-FEM models). The variation of these two modal parameters in terms of $\kappa$ for all the soil-bridge systems are included in Figures 7 and 8, respectively.

\subsubsection{Effect of soil properties on identified natural frequencies}

In Figure 7 the fundamental frequency variations, with respect to infinitely rigid soil conditions, experienced by the bridges are represented with circles. These results are calculated using the BEM-FEM model described in section 2.2. Figures in the same row correspond to the same soil shear-wave velocity, while figures in the same column correspond to the same value of soil material damping. In all the plots, the analytical solution for the fundamental frequency variation of an elastically supported (ES) Bernoulli-Euler beam with identical elastic supports of $K_{v}$ vertical stiffness has been represented in thick black trace [6]. Finally, in each graph different frequency bands are distinguished in shaded areas, and circle sizes are proportional to the lengths of the bridges.

The vertical flexibility of the soil-foundations leads to a reduction in the fundamental frequency of the bridges under study. This reduction is more evident in the case of bridges with higher natural frequencies (and therefore, higher values of $\kappa)$. This is consistent with the results presented in section 3.1. For each frequency group, bridges with longer spans are most affected by soil conditions. This is due to the fact that longer bridges present higher $\kappa$ values [24].

From the analysis of the results presented it may be concluded that: (i) the frequency variation experienced by the structures when SSI is included follows the general trend shown by the ES BE beam in terms of the static relative stiffness parameter $\kappa$. The frequency dependence of the soil-foundation stiffness is not relevant, especially for low $\kappa$ values and long bridges; (ii) soil-bridge systems with similar $\kappa$ values show similar frequency variations, independently of the soil properties and the beam natural frequency in the absence of SSI; (iii) for each soil type and frequency band, shorter bridges show a slightly higher deviation with respect to the analytical solution of the ES beam; (iv) these tendencies take place for different soil material damping levels, and the influence of this parameter is almost negligible regarding the variation of the bridges fundamental frequency. This issue was anticipated in section 3.1 for low frequency ranges. 


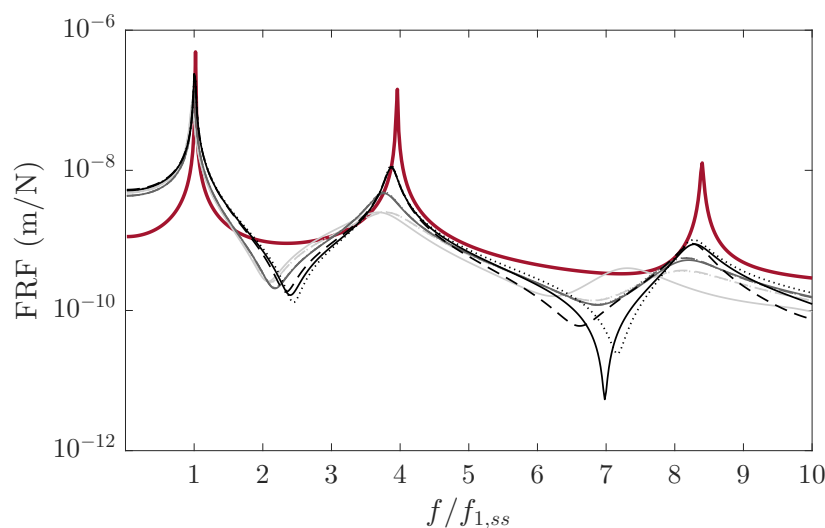

(a) $f_{1,000}$

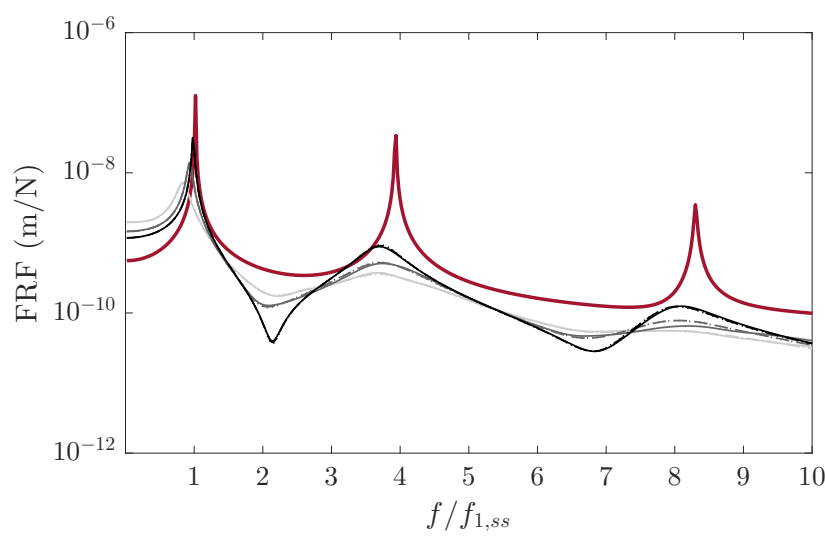

(c) $f_{1,070}$

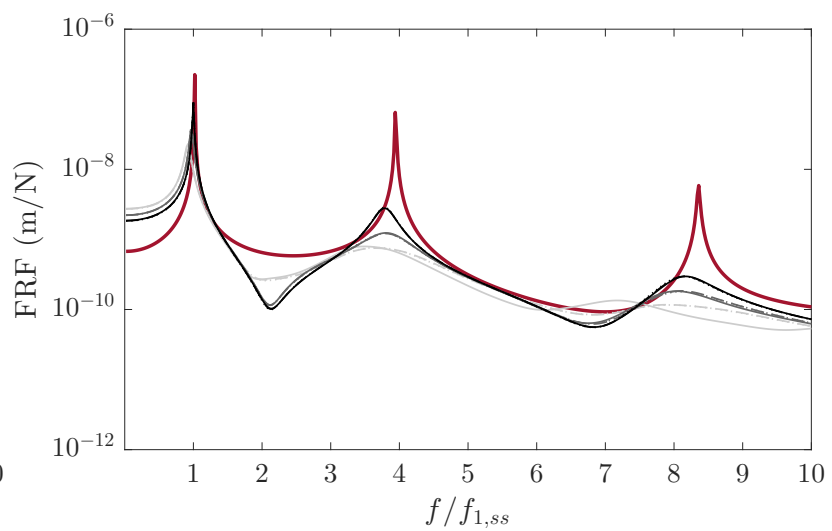

(b) $f_{1,035}$

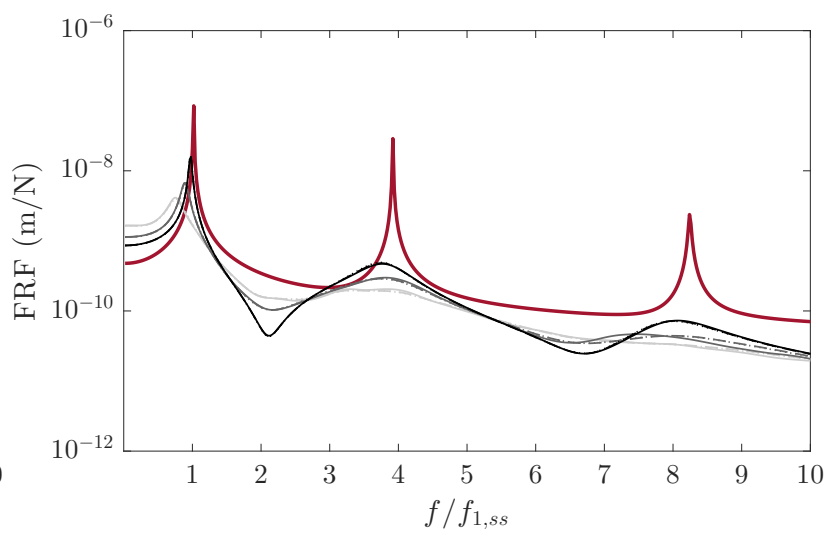

(d) $f_{1,100}$

Figure 5: FRF of a bridge of $L=15 \mathrm{~m}$ and soil properties: $c_{s}=150 \mathrm{~m} / \mathrm{s}, \quad c_{s}=220 \mathrm{~m} / \mathrm{s}$ and $c_{s}=365 \mathrm{~m} / \mathrm{s}$. Bridge response in SS case. Considering the following damping ratios: $\zeta_{s}=0.000$ (solid lines), $\zeta_{s}=0.025$ (dashed lines) and $\zeta_{s}=0.050$ (dotted lines)

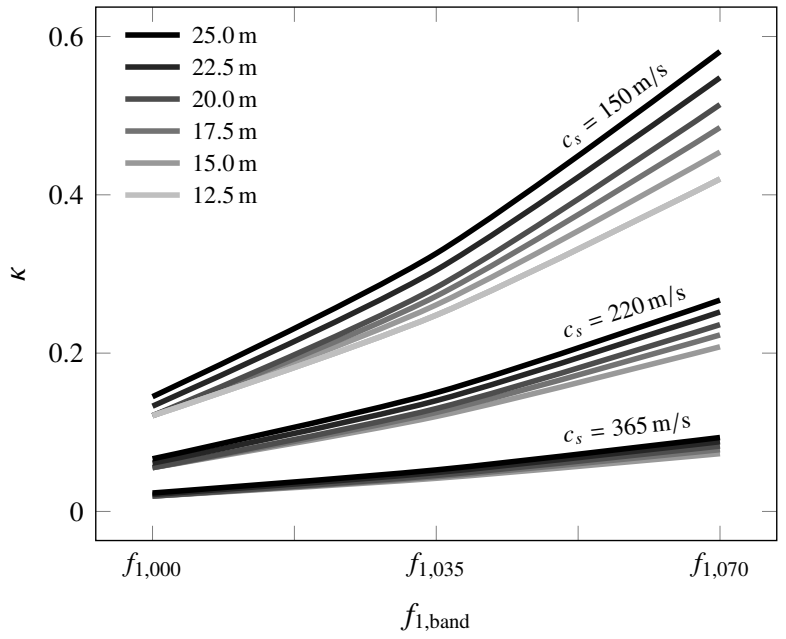

Figure 6: Dimensionless ratio $\kappa$ for the soil-bridge systems under study

\subsubsection{Effect of soil properties on identified modal dampings}

In Figure 8 the values of structural damping in the fundamental mode identified from the bridges response for the ranges of soil properties under consideration are represented with circles.

The structural damping ratio including SSI effects $\left(\zeta_{1}\right)$ is identified from the free damped response of the bridges through Logarithmic decrement. As in Figure 7, different frequency bands are distinguished in shaded areas, and circle sizes are proportional to the bridges lengths. The modal damping measured from the bridge response strongly depends on the value taken by the relative flexibility $\kappa$. As the flexibility of the soil increases (higher $\kappa$ levels for the same structure), so does the identified damping due to the wave radiation through the soil. Again, for the same soil properties, structures with higher fundamental frequencies in the absence of soil exhibit higher increments of structural damping when SSI is considered. This is again consistent with the analysis presented in section 3.1. On the other hand, the influence of the soil material damping on the identified structural damping is minimal in the fundamental mode. As it was exposed in the previous section, soil damping only modifies the structural response during a short transient, due to the relative wavelengths of the soil and the bridges. Therefore, the influence of soil damping is expected to be significant only at higher frequencies than the bridge fundamental one. 


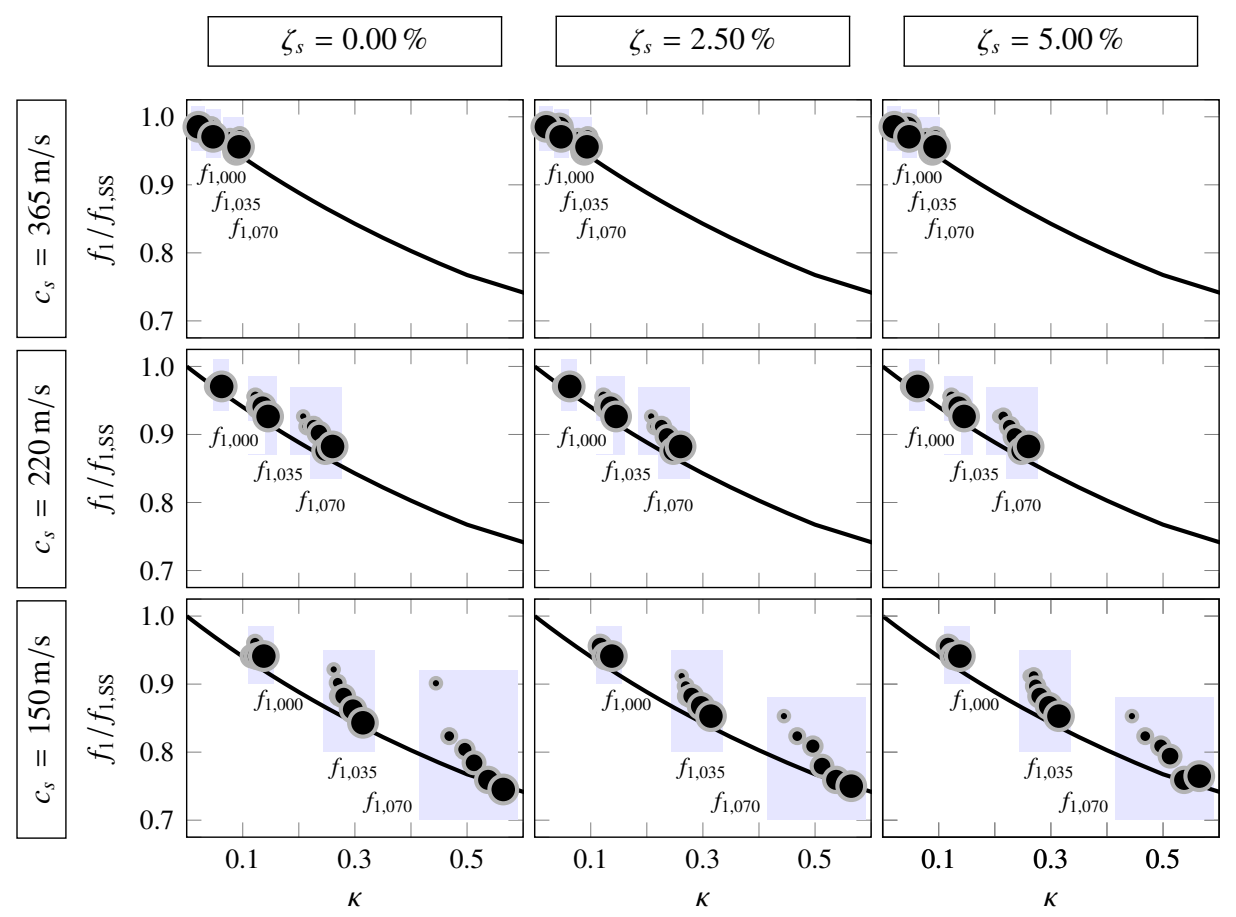

Figure 7: Bridge identified fundamental frequency vs. $\kappa$. ceCl $L_{i}-$ Analytical ES beam case

\subsection{Free vibration response under a $S M L$}

According to [6] the dynamic amplification of a SS or ES beam at resonance caused by the circulation of MML is closely related to the free vibrations that the same beam experiences after the passage of each single load travelling at the same speed. The load travelling at certain speeds, induces on the beam a remarkably high response (maximum free vibrations) and, at some other speeds, the oscillations when the load leaves the beam are almost negligible (cancellation of free vibration). These two phenomena are independent of the periodicity of the loads, and take place for a single moving load. The aim of this section is to evaluate how SSI affects these two conditions. In [24] preliminary results were presented in this regard. Now the response of the complete ensemble of soil-bridge systems defined in section 2.3 is obtained in free vibration after the circulation of a SML in a wide range of speeds.

Let us define a dimensionless speed $K_{1}^{S S}$ referred to the bridges fundamental frequency in the absence of soil,

$$
K_{1}^{\mathrm{SS}}=\frac{\Omega_{1}^{\mathrm{SS}}}{\omega_{1}^{\mathrm{SS}}}=\frac{\pi V}{\omega_{1}^{\mathrm{SS}} L}
$$

In Eq. (10), $\omega_{1}^{\mathrm{SS}}$ is the fundamental circular frequency of the bridge with SS boundary conditions, while $\Omega_{1}^{\mathrm{SS}}=\pi V / L$ is used to represent the forcing frequency of the SML.

The bridges under analysis are those indicated in Figure 3, considering soil shear wave velocities $c_{s}=$ $\{150,220,365, \infty\} \mathrm{m} / \mathrm{s}$. Structure and soil material damping is neglected in this study. For each soil-bridge system, 70 evenly spaced values of $K_{1}^{S S}$ have been selected between 0.1 and 0.5 .
As detailed in [6] this range suffices to cover the circulation speeds expected in nowadays railway systems. In order to accurately capture the variation of the cancellation conditions when SSI is included, twenty additional speeds are computed within the ranges $[0.85,1.15] K_{1, c i}^{S S}$, where $K_{1, c i}^{S S}$ represents the ith nondimensional cancellation speed of the first mode in the SS case. For each circulation speed, the maximum vertical displacement at the bridge mid-span section is computed, once the load has left the structure. This result, divided by the static displacement, leads to the dimensionless quantity $R$ represented in Figure 9. As the response is obtained at mid-span and due to the time-step used in the numerical integration, $R$ basically corresponds to the contribution of the fundamental mode of the beam to the total response.

In Figure 9 all the curves obtained for the 72 soil-bridge systems under study ( 18 bridges $\times 4$ soil types) are plotted simultaneously. The curves are distinguished using a colour code based on the value of parameter $\kappa$. From the analysis performed, the following can be concluded: (i) maximum free vibration and cancellation conditions alternate with the increase of the load speed, in the same way that happens in the absence of soil; (ii) far from cancellation conditions, models without SSI always predict a higher response than those including SSI; (iii) as $\kappa$ increases for softer soils and bridges with higher natural frequencies, the amplification reduces between two cancellation conditions; (iv) the cancellation speeds slightly decrease as the relative stiffness $\kappa$ increases. This variation is associated with the descent of the structure fundamental frequency with the soil flexibility.

An accurate prediction of the cancellation speeds is crucial, 


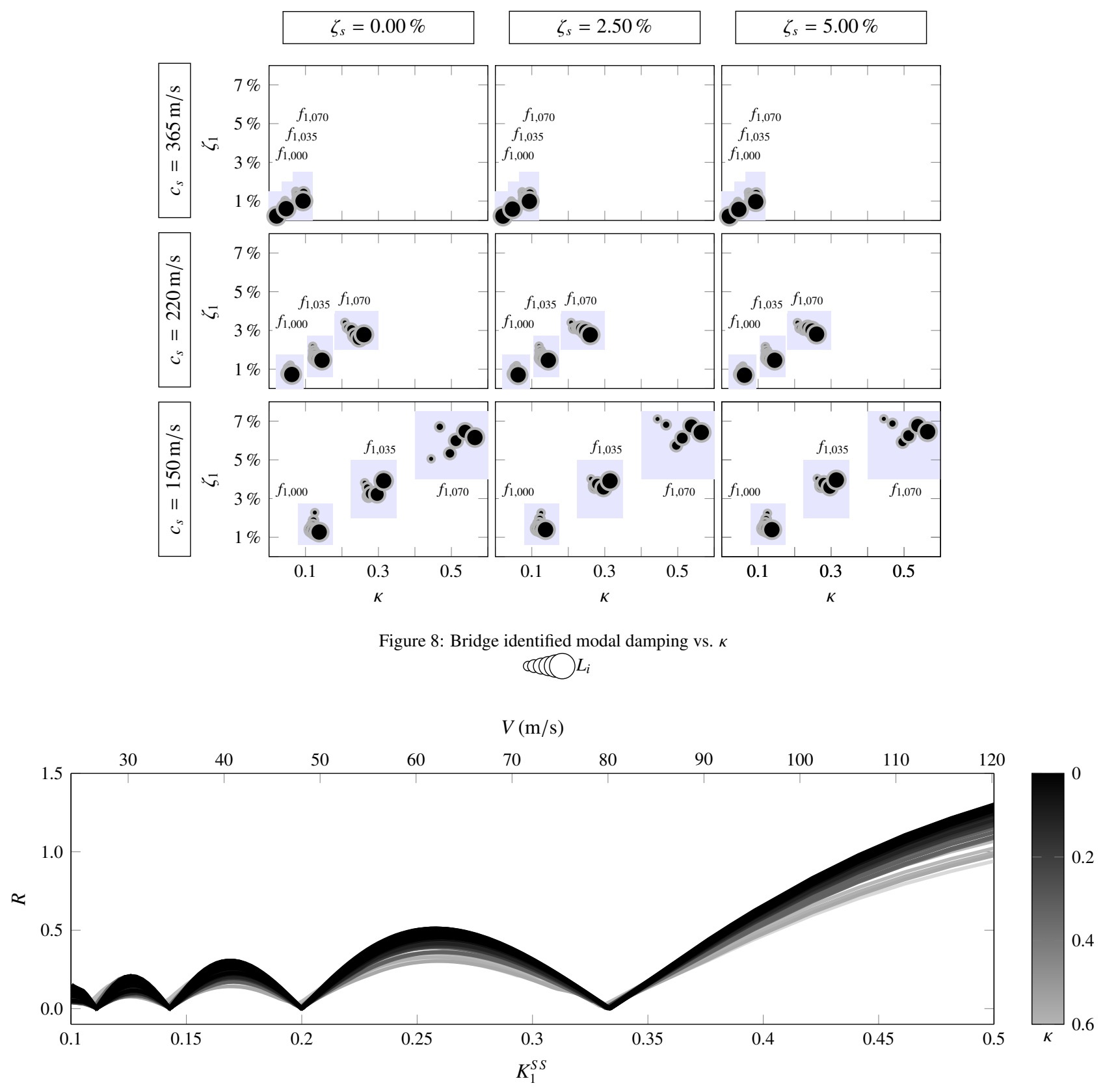

Figure 9: Non-dimensional free vibration amplitude as a function of the speed.

for instance, when planning an experimental test with the aim of measuring structural parameters $i$. e., damping. In Figures 10 (a) and 10(b) the reduction of the cancellation speeds for the first and second cancellation conditions of the coupled soil-bridge systems $\left(V_{1, c 1}\right.$ and $\left.V_{1, c 2}\right)$ with respect to the corresponding SS case cancellation speeds $\left(\bar{V}_{1, c 1}\right.$ and $\left.\bar{V}_{1, c 2}\right)$ are obtained and represented in terms of $\kappa$. The first sub-index (1) is used to designate cancellations of the bridges fundamental mode, and first cancellation (c1) refers to that happening at the highest speed. In the same plots the reduction of the cancellation speeds is also represented in thick trace for the analytical ES BE beam [6]. The relative static stiffness parameter $\kappa$ proves to be again an important factor, also in the prediction of the can- cellation speeds, especially for moderate $\kappa$ values. Soil-bridge models obtained from different combinations of span length, bridge frequency and soil type, present similar values of the $V_{1, c i} / \bar{V}_{1, c i}$ ratio for similar values of $\kappa$. The deviation with respect to the analytical solution of the ES case is again slightly higher for shorter bridges.

The cancellation speeds experience a noticeable variation with the soil flexibility in the case of beams with the longest spans, highest fundamental frequencies, and for the most flexible soil of the AASHTO classification. The reduction experienced by the $2^{\text {nd }}$ cancellation speed shows an upper bound of $\sim 10 \%$, a slightly higher value than that of the $1^{\text {st }}$ cancellation speed $(\sim 7 \%)$ in the aforementioned cases, where the influence 

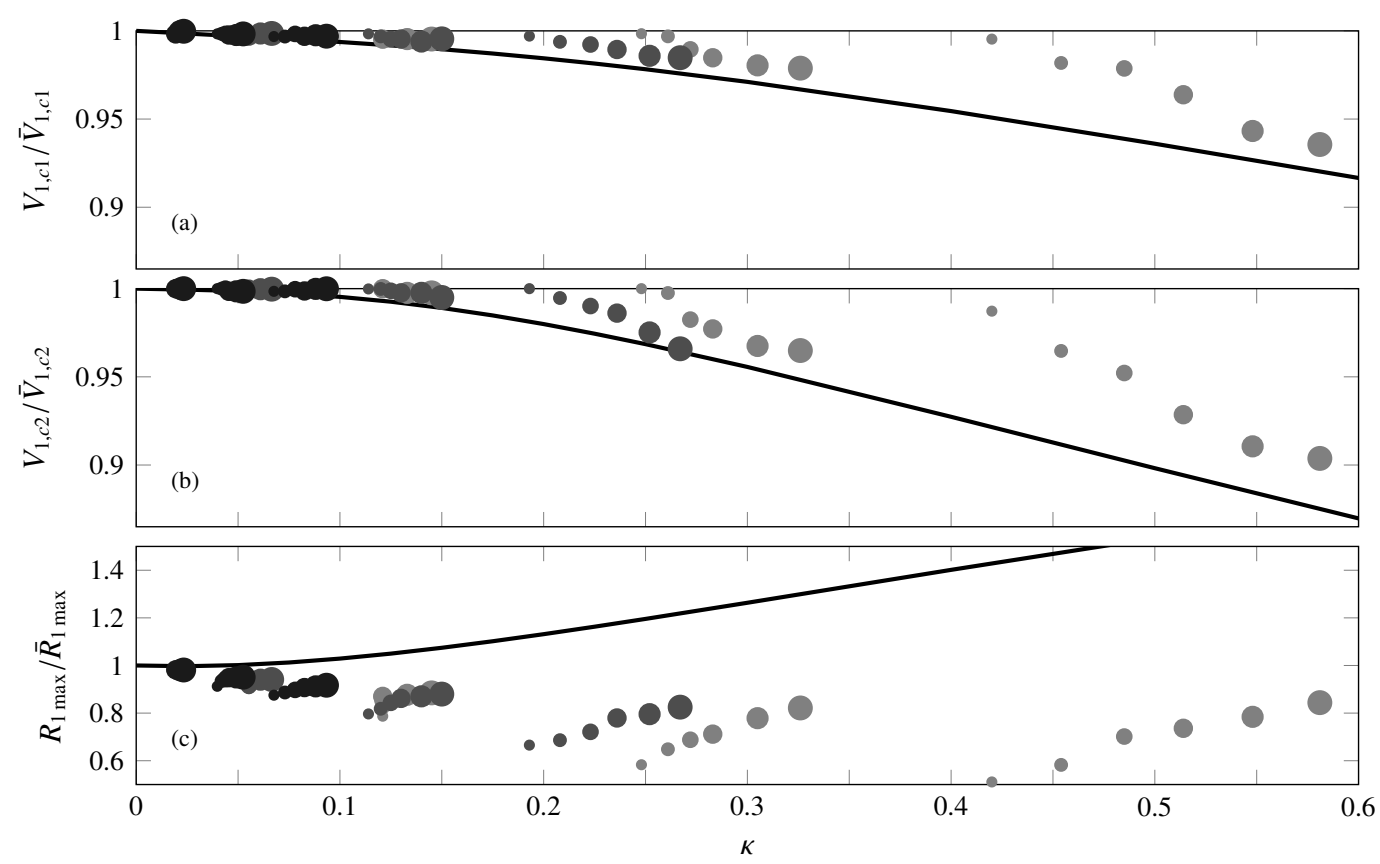

Figure 10: Variation of the cancellation speeds (Figures a,b) and the maximum amplitude of the free vibrations (Figure c) with $\kappa$

$$
\text { - ES beam } \mathbb{C} C L_{i} \square c_{s}=365 \mathrm{~m} / \mathrm{s} \square c_{s}=220 \mathrm{~m} / \mathrm{s} \square c_{s}=150 \mathrm{~m} / \mathrm{s}
$$

\section{of SSI maximises.}

Finally, in Figure 10(c) the reduction of the amplification at the first maximum free vibration condition $\left(R_{1, \max }\right)$ referred to the same value for the case $\kappa=0$ (which happens for $K_{1}^{S S}=0.2576$ ) is represented. As it may be observed, out of the vicinity of each cancellation speed, SSI leads to a reduction of the bridge maximum free vibration amplitude. This behaviour differs from the one observed in the ES case, where the maximum level of free vibrations of the ES beam may be associated to high or low values of the supports flexibility depending on the non-dimensional speed, and a SS model of the beam does not always lead to the most conservative response in terms of structural vibration levels (details may be contrasted in [6]).

The reduction obtained for different soil-bridge systems is similar for similar values of $\kappa$, for moderate $\kappa$ values. This reduction tends to increase as the soil becomes more flexible. This effect is attributed to the radiation damping of the soil, only present in the BEM-FEM models.

Knowing the conditions for maximum free vibration and cancellation of a soil-bridge system under a SML is relevant as if the same system is subjected to periodic MML travelling at a resonant speed, and this speed coincides with a cancellation condition, the amplification will be minimal and the resonant peak will become imperceptible. If, on the other hand, the resonant speed is close to a maximum free vibration condition, important vibration levels should be expected.

\section{Case study}

In this section the dynamic performance of a real railway bridge subjected to the action of trains travelling at different speeds is analysed using the BEM-FEM model described in section 2.1 . The aim is to exemplify the tendencies in the structural response with the soil properties detected in the previous sections and evaluate it under resonant and non-resonant conditions. The bridge considered is similar to an existing structure, Guadiana bridge, that belongs to the Madrid-Alcázar de San Juan-Jaén conventional railway line in Spain. The transformation of this line into a High-Speed one may eventually occur. The bridge consists of two identical SS bays crossing the Guadiana River (see Figure 11). The bridge deck is composed by two single track independent decks of $5.075 \mathrm{~m}$ width, exhibiting a beam-type behaviour. Each deck consists of a $25 \mathrm{~cm}$ thickness concrete slab resting over five pre-stressed concrete beams with a $75 \mathrm{~cm}$ height rectangular cross-section (see Figure 12). Both decks carry a single ballasted track with an equal eccentricity of $0.6375 \mathrm{~m}$ with respect to each deck longitudinal axis. A beam model for each single track deck is considered in a first approach. Additional details of the deck geometry may be consulted in [8]. The values considered for the bridge fundamental frequency, length and mass per unit length are 10.065 $\mathrm{Hz}, 13 \mathrm{~m}$ and $9360 \mathrm{~kg} / \mathrm{m}$, respectively. A structure damping of $1.5 \%$ is assigned according to Eurocode [5].

The response of the bridge is analysed under the circulation of the High-Speed load model HSLM-A3 from Eurocode [5]. This train is selected as it induces second and third resonances of the bridge fundamental frequency at $362 \mathrm{~km} / \mathrm{h}$ and at 242 $\mathrm{km} / \mathrm{h}$, respectively, with important transverse acceleration levels. The theoretical resonant or critical speeds associated to the characteristic distance $d_{A 3}$ of train HSLM-A3 for SS conditions may be obtained as 

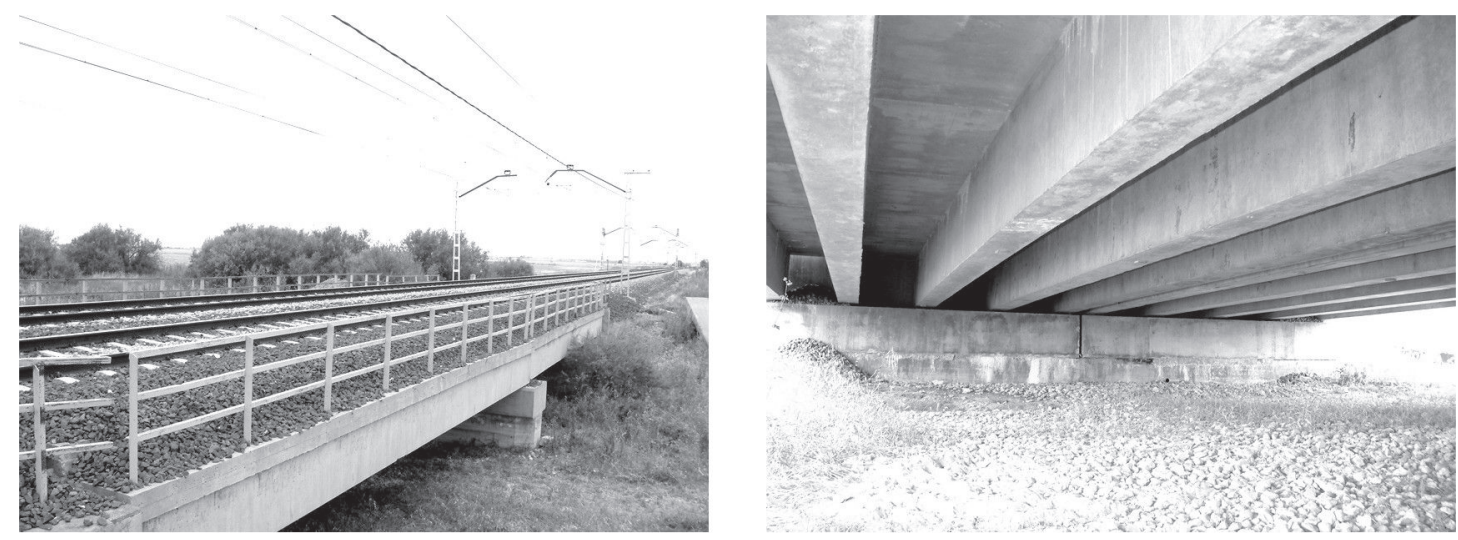

Figure 11: Railway bridge under study

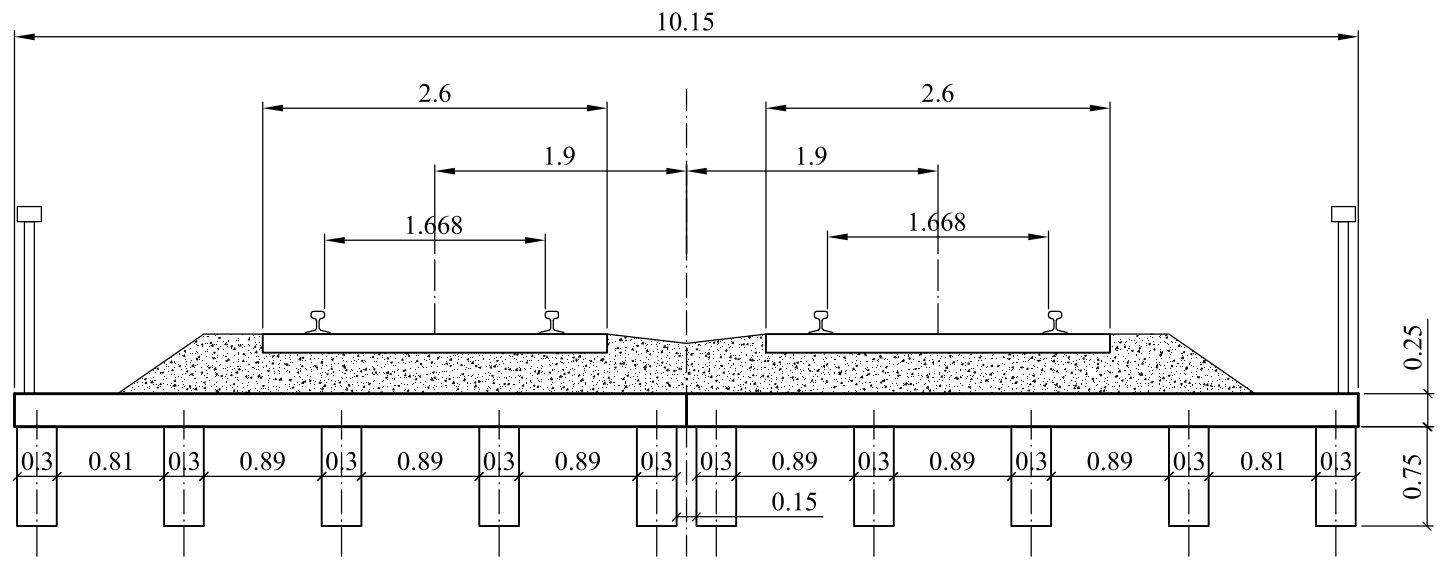

Figure 12: Railway bridge cross section

$$
V_{R 2}=\frac{d_{A 3} f_{1}}{2} \quad V_{R 3}=\frac{d_{A 3} f_{1}}{3}
$$

In Figure 13(a) the maximum acceleration at mid-span of the bridge deck is represented versus the travelling speed for different soil flexibilities $\left(c_{s}=\{150,220,365\} \mathrm{m} / \mathrm{s}\right)$ and constant soil material damping of $5.0 \%$. The bridge response for infinitely rigid soil conditions (SS case) is included as well for comparison purposes. The second (R2) and third (R3) resonance peaks are apparent and take place close to the theoretical speeds when SSI is disregarded. In the same plot, the acceleration limit for ballasted tracks of $3.5 \mathrm{~m} / \mathrm{s}^{2}$ is indicated as a reference [5].

As the soil stiffness decreases (lower $c_{s}$ values), resonant speeds shift to lower values. This is a consequence of the reduction experienced by the bridge fundamental frequency when soil structure interaction effects are included. Close to resonance, the bridge amplification is affected noticeably by the flexibility of the soil, and reduces as the soil becomes more flexible. For the softest soil considered, $c_{s}=150 \mathrm{~m} / \mathrm{s}$, resonant peaks are not perceptible in the structure response. The aforementioned tendency takes place for both resonant orders, although in a slightly higher proportion in the case of the second resonance. In Figure 14(b) the acceleration time history at mid-span at the second resonance $(\mathrm{V}=362 \mathrm{~km} / \mathrm{h})$ is represented for the four soil flexibilities considered in Figure 13(a).
It can be observed how the soil does not pay an important role during the entrance of the train on the bridge (first second) and how it drastically reduces the response of the structure as the resonance regime builds up.

For non-resonant speeds (see Figure 13(a) between 275 and $325 \mathrm{~km} / \mathrm{h}$ ), the bridge amplification including SSI is very similar to that of the SS case. This becomes evident in Figure 14(a), where the acceleration time-history at mid-span is plotted for $\mathrm{V}=300 \mathrm{~km} / \mathrm{h}$. The curves for the different soil flexibilities almost overlap.

In Figure 13(b) the response of the bridge is represented in terms of the train speed maintaining the soil shear wave velocity constant and equal to $220 \mathrm{~m} / \mathrm{s}$, and for three levels of soil material damping. Again, the response corresponding to infinitely rigid soil conditions is included. The resonant peak amplitudes reduce due to the wave radiation through the soil but the soil material damping does not affect these amplitudes. These results are consistent with those presented in the previous sections. The peaks correspond to resonances of the fundamental mode of the bridge and, as exposed in section 3.1, soil damping may be perceptible in the bridge response only at higher frequencies. 

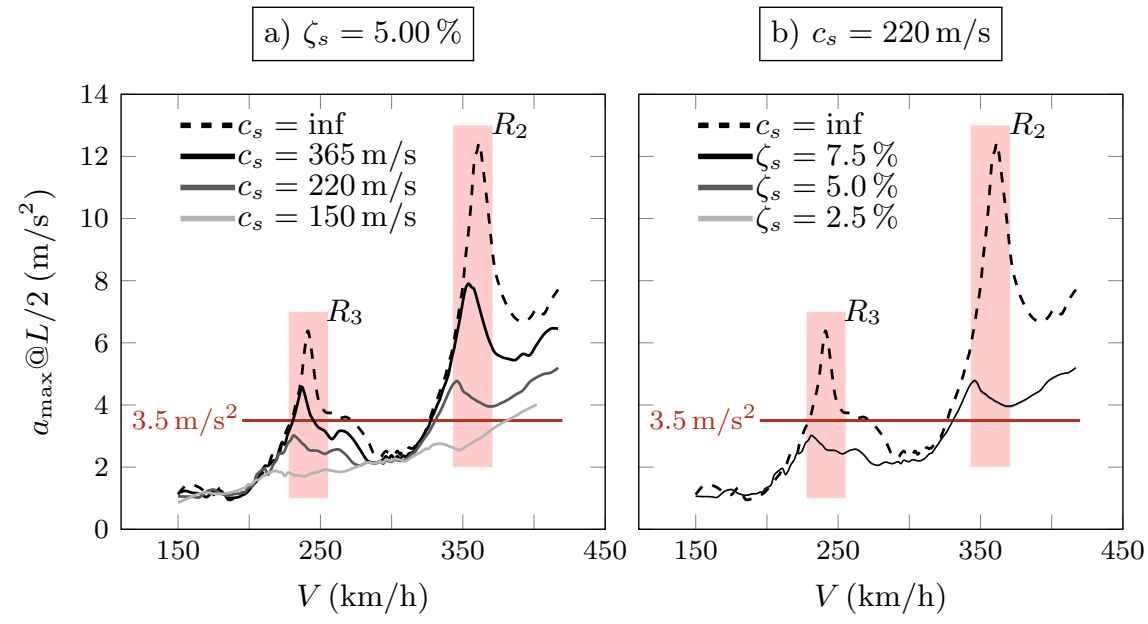

Figure 13: Maximum acceleration at mid-span vs. travelling speed for different soil properties HSLM-A3 train, $L=13 \mathrm{~m}, f_{1}=10.065 \mathrm{~Hz}, m=9360 \mathrm{~kg} / \mathrm{m}, \zeta_{0}=1.49 \%$

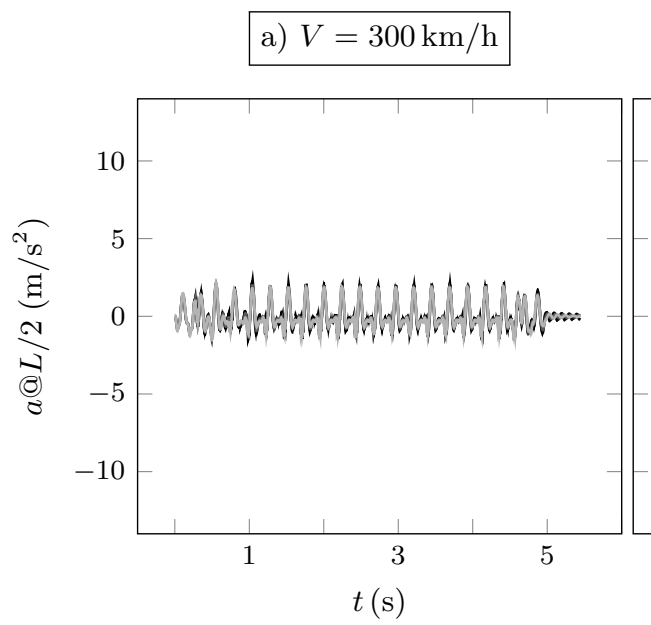

b) $V=362 \mathrm{~km} / \mathrm{h}$

Figure 14: Vertical acceleration time history

HSLM-A 3 train, $L=13 \mathrm{~m}, f_{1}=10.065 \mathrm{~Hz}, m=9360 \mathrm{~kg} / \mathrm{m}, \zeta_{0}=1.49 \%$.

- - SS, - $c_{s}=365 \mathrm{~m} / \mathrm{s},-c_{s}=220 \mathrm{~m} / \mathrm{s},-c_{s}=150 \mathrm{~m} / \mathrm{s}$

\section{Conclusions}

SSI effects on the dynamic response of SS bridges under railway traffic are investigated in this contribution, using a fully coupled 3D BEM-FEM model integrated in the time domain. FE Bernoulli-Euler beam models are used to represent the bridges superstructures. FE infinitely rigid plates coupled to an elastic single layer half-space boundary element model represent the substructure-soil systems, using a simplistic approach. An ensemble of bridges is defined covering length spans and typologies susceptible to experience an inadequate performance in terms of deck transverse acceleration. Also, different soil flexibilities and material dampings are considered covering the AASHTO classification for soils ranging from considerably flexible soils to infinitely rigid support conditions. Consequently, a cluster of 180 soil-bridge systems is defined and analysed. From the sensitivity analysis performed, the following is concluded:
- SSI leads to a reduction of the bridges fundamental frequency following the general trend of the ES BE beam in terms of the static relative stiffness parameter $\kappa$. The frequency dependence of the soil-foundation stiffness does not play an important role in the bridge fundamental frequency variation, especially for low $\kappa$ values (stiff soils and low frequency bridges) and long bridges. Soil-bridge systems with similar $\kappa$ values show comparable frequency variations, regardless of the soil properties and the bridges initial natural frequencies.

- The bridge modal damping associated to the first mode strongly depends on the relative flexibility $\kappa$. As the flexibility of the soil increases, so does the identified damping due to the wave radiation through the soil. For the same soil properties, structures with higher fundamental frequencies exhibit higher increments of structural damping when SSI is considered. 
- The influence of soil material damping on the identified bridges natural frequencies and modal dampings in the fundamental mode is negligible. A noticeable effect of this magnitude should be expected for higher frequencies.

- Maximum free vibration and cancellation conditions alternate as the speed increases in the free vibration response of the bridges after the passage of a SML. Cancellation speeds decrease with the flexibility of the soil, especially for structures with high frequencies. Far from the cancellation conditions, models not considering SSI always predict a higher response than those including SSI.

Finally, the performance of a real structure is analysed under the circulation of a train of moving loads in a wide range of circulating speeds. The presented results show that (i) as the soil stiffness decreases, resonant speeds shift to lower values; (ii) close to resonance, the bridge amplification is affected noticeably by the flexibility of the soil, and reduces as the soil becomes more flexible; (iii) for non-resonant speeds, the effect of the soil flexibility in minimal; (iv) soil material damping effect on the bridge response is not perceptible at resonant peaks associated with the fundamental mode of the structure, regardless of the resonance order.

Incorporating soil-structure interaction in the analysis of new or existing simply-supported bridges for design or retrofitting purposes could be of great importance, due to the influence of soil flexibility in the assessment of the Serviceability Limit Sate of vertical acceleration. In-depth studies should be addressed in forthcoming contributions aimed at establishing the practical importance of incorporating the soil model in the prediction of the bridge peak response considering realistic sub-structure geometries and experimentally measured properties of the soil. Experimental validation studies of real structures under railway traffic analysing the effects of considering or not SSI at resonance and not resonance conditions should be conducted.

\section{Acknowledgements}

The authors would like to acknowledge the financial support provided by (i) the Spanish Ministry of Economy and Competitiveness under the research project [BIA2013-43085-P], (ii) the Andalusian Scientific Computing Centre (CICA) and (iii) Universitat Jaume I under the research project [P1-1B201554]. This work falls within the initiation of research project BIA2016-75042-C2 financed by the Spanish Ministry of Economy and Competitiveness.

\section{References}

[1] ERRI D214, Rail bridges for speeds $>200 \mathrm{~km} / \mathrm{h}$. Final report. Part a. Synthesis of the results of D 214 research, European Rail Research Institute, 1999.

[2] T. Ishibashi, Shinkansen structures in Japan, in: FEUP (Ed.), Workshop: Bridges for high-speed railways., 2004.

[3] [3]E. Moliner, M. Martínez-Rodrigo, P. Museros, Dynamic performance of existing double track railway bridges at resonance with the increase of the operational line speed, Engineering Structures 132 (2017) 98 - 109. doi:http://dx.doi.org/10.1016/j.engstruct.2016.11.031.
URL http://www.sciencedirect.com/science/article/pii/ S0141029616312639

[4] R. Le, B. Ripke, M. Zacher, Influence of bridge dynamics on ballast deterioration on high-speed lines, in: World Congress on Railway Research. Book of paper summaries, 1999, p. 159.

[5] European Committee for Standardization EN 1991-2, Eurocode 1 - Actions on Structures - Part 2: Traffic loads on bridges, CEN, Brussels, 2002.

[6] P. Museros, E. Moliner, M. Martínez-Rodrigo, Free vibrations of simplysupported beam bridges under moving loads: Maximum resonance, cancellation and resonant vertical acceleration, Journal of Sound and Vibration 332 (2) (2013) $326-345$.

[7] J. Wallin, J. Laeander, R. Karoumi, Strengthening of a steel railway bridge and its impact on the dynamic response of passing trains, Engineering Structures 33 (2011) 635-646.

[8] M. Martínez-Rodrigo, J. Lavado, P. Museros, Dynamic performance of existing high-speed railway bridges under resonant conditions retrofitted with fluid viscous dampers, Engineering Structures 32 (2010) 808-828.

[9] M. Ülker Kaustell, R. Karoumi, C. Pacoste, Simplified analysis of the dynamic soil-structure interaction of a portal frame railway bridge, Engineering Structures 32 (11) (2010) 3692 - 3698. doi:http://dx.doi.org/10.1016/j.engstruct.2010.08.013.

URL http://www.sciencedirect.com/science/article/pii/ S0141029610003020

[10] M. Klasztorny, J. Langer, Dynamic response of single-span beam bridges to a series of moving loads, Earthquake Engineering and Structural Dynamics 19 (1990) 1107-1124.

[11] Y. Yang, J. Yau, L. Hsu, Vibration of simple beams due to trains moving at high speeds, Engineering Structures 19(11) (1997) 936-944.

[12] L. Frýba, A rough assessment of railway bridges for high speed trains, Engineering Structures 23 (2001) 548-556.

[13] P. Museros, E. Alarcón, Influence of the second bending mode on the response of high-speed bridges at resonance, Journal of Structural Engineering 131 (3) (2005) 405-415.

[14] E. Savin, Dynamic amplification factor and response spectrum for the evaluation of vibrations of beams under successive moving loads, Journal of Sound and Vibration 248 (2) (2001) 267 - 288.

[15] J. Yau, Y. Yang, Vertical accelerations of simple beams due to successive loads traveling at resonant speeds, Journal of Sound and Vibration 289 (2006) $210-228$.

[16] C. Sudheesh-Kumar, C. Sujatha, K. Shankar, Vibration of simply supported beams under a single moving load: A detailed study of cancellation phenomenon, International Journal of Mechanical Sciences 99 (2015) 4047.

[17] J.-R. Cho, K. Jung, K. Cho, J.-W. Kwark, Y. J. Kim, B.-S. Kim, Determination of the optimal span length to minimize resonance effects in bridges on high-speed lines, Proceedings of the Institution of Mechanical Engineers, Part F: Journal of Rail and Rapid Transit (2014) 1-10.

[18] G. Mylonakis, G. Gazetas, Seismic soil-structure interaction: beneficial or detrimental?, Journal of Earthquake Engineering 04 (03) (2000) 277 301. doi:http://dx.doi.org/10.1142/S1363246900000175.

URL http://www.worldscientific.com/doi/abs/10.1142/ S1363246900000175

[19] J. Lu, X. Sha, J. Wu, Resonance and cancellation phenomena caused by equidistant moving loading in a periodic structure - a pile-supported periodic viaduct, European Journal of Mechanics/A solids 59 (2016) 114 123.

[20] Y. Wu, Y. Yang, A semi-analytical approach for analyzing ground vibrations caused by trains moving over elevated bridges, Soil D 24 (2004) 949-962.

[21] Y. Cao, H. X. X. Li, A semi-analytical/fem model for predicting ground vibrations induced by high-speed train through continuous girder bridge, Journal of Mechanical Science and Technology 26 (8) (2012) 2485-2496.

[22] L. Sun, W. Xie, X. He, T. Hayashikawa, Prediction and mitigation analysis of ground vibrations caused by running high-speed trains on rigidframe viaducts, Earthquake Engineering and Engineering Vibration 15 (2016) 31-47.

[23] H. Takemiya, X. C. Bian, Shinkansen high-speed train induced ground vibrations in view of visduct-ground interaction, Soil Dynamics and Earthquake Engineering 27 (2007) 506-520.

[24] A. Doménech, M. D. Martínez-Rodrigo, A. Romero, P. Galvín, On the basic phenomenon of soil-structure interaction on the free vibration re- 
sponse of beams: Application to railway bridges, Engineering Structures 125 (2016) 254-265.

URL http://www.sciencedirect.com/science/article/pii/ S0141029616303236

[25] E. Moliner, Dynamic behaviour of high-speed railway bridges and its retrofit with passive viscoelastic dampers, Ph.D. thesis, Departamento de Ingeniería de la Construcción y Proyectos de Ingeniería Civil, Universidad Politécnica de Valencia (2012 (in Spanish)).

[26] L. Frýba, Dynamics of Railway Bridges, Thomas Telford, 1996.

[27] S. L. Grassie, R. W. Gregory, D. Harrison, K. L. Johnson, The dynamic response of railway track to high frequency vertical excitation, Journal of Mechanical Engineering Science 24 (2) (1982) 77-90. arXiv:http://jms.sagepub.com/content/24/2/77.full.pdf+html, doi:10.1243/JMES_JOUR_1982_024_016_02.

URL http://jms. sagepub. com/content/24/2/77.abstract

[28] C. Rebelo, L. S. da Silva, C. Rigueiro, M. Pircher, Dynamic behaviour of twin single-span ballasted railway viaducts - field measurements and modal identification, Engineering Structures 30 (9) (2008) 2460 - 2469.

[29] T. Rauert, H. Bigelow, B. Hoffmeister, M. Feldmann, On the prediction of the interaction effect caused by continuous ballast on filler beam railway bridges by experimentally supported numerical studies, Engineering Structures 32 (12) (2010) 3981 - 3988.

[30] C. Rigueiro, C. Rebelo, L. S. da Silva, Influence of ballast models in the dynamic response of railway viaducts, Journal of Sound and Vibration 329 (15) (2010) $3030-3040$.

[31] W. Zhai, S. Wang, N. Zhang, M. Gao, H. Xia, C. Cai, C. Zhao, High-speed train-track-bridge dynamic interactions - part ii: experimental validation and engineering application, International Journal of Rail Transportation 1 (1-2) (2013) 25-41. arXiv:http://dx.doi.org/10.1080/23248378.2013.791497, doi:10.1080/23248378.2013.791497. URL http://dx.doi.org/10.1080/23248378.2013.791497

[32] W. Zhai, H. Xia, C. Cai, M. Gao, X. Li, X. Guo, N. Zhang, K. Wang, High-speed train-track-bridge dynamic interactions - part i: theoretical model and numerical simulation, International Journal of Rail Transportation 1 (1-2) (2013) 324. arXiv:http://dx.doi.org/10.1080/23248378.2013.791498, doi:10.1080/23248378.2013.791498.

URL http://dx.doi.org/10.1080/23248378.2013.791498

[33] A. Doménech, P. Museros, M. Martínez-Rodrigo, Influence of the vehicle model on the prediction of the maximum bending response of simply-supported bridges under high-speed railway traffic, Engineering Structures 72 (2014) 123 - 139. doi:http://dx.doi.org/10.1016/j.engstruct.2014.04.037.

[34] T. Arvidsson, R. Karoumi, Train-bridge interaction - a review and discussion of key model parameters, International Journal of Rail Transportation 2 (3) (2014) 147186. arXiv:http://dx.doi.org/10.1080/23248378.2014.897790, doi:10.1080/23248378.2014.897790.

URL http://dx.doi .org/10.1080/23248378.2014.897790

[35] G. Kouroussis, D. Connolly, O. Verlinden, Railway-induced ground vibrations - a review of vehicle effects, International Journal of Rail Transportation 2 (2) (2014) 69110. $\quad$ arXiv:http://dx.doi.org/10.1080/23248378.2014.897791, doi:10.1080/23248378.2014.897791.

URL http://dx.doi .org/10.1080/23248378.2014.897791

[36] S. Erhan, M. Dicleli, Effect of dynamic soil-bridge interaction modeling assumptions on the calculated seismic response of integral bridges, Soil Dynamics and Earthquake Engineering 66 (2014) 42 - 55. doi:http://dx.doi.org/10.1016/j.soildyn.2014.06.033.

URL http://www.sciencedirect.com/science/article/pii/ S0267726114001572

[37] P. Galvín, A. Romero, A 3D time domain numerical model based on halfspace Green's function for soil-structure interaction analysis, Computational Mechanics 53 (2014) 1073-1085. doi:10.1007/s00466-013-09491.

[38] M. Prabucki, O. von Estorff, Dynamic response in the time domain by coupled boundary and finite elements, Computational Mechanics 6 (1) (1990) 35-46.

[39] P. Galvín, A. Romero, A MATLAB toolbox for soil-structure interaction analysis with finite and boundary elements, Soil
Dynamics and Earthquake Engineering 57 (2014) 10 - 14. doi:http://dx.doi.org/10.1016/j.soildyn.2013.10.009.

URL http://www.sciencedirect.com/science/article/pii/ S0267726113002261

[40] A. Romero, P. Galvín, J. Domínguez, 3D non-linear time domain FEM-BEM approach to soil-structure interaction problems, Engineering Analysis with Boundary Elements 37 (3) (2013) 501 - 512. doi:http://dx.doi.org/10.1016/j.enganabound.2013.01.001.

URL http://www.sciencedirect.com/science/article/pii/ S0955799713000052

[41] P. Galvín, A. Romero, J. Domínguez, Fully three-dimensional analysis of high-speed train-track-soil-structure dynamic interaction, Journal of Sound and Vibration 329 (24) (2010) 5147 - 5163. doi:http://dx.doi.org/10.1016/j.jsv.2010.06.016.

URL http://www.sciencedirect.com/science/article/pii/ S0022460X10004062

[42] O. Zienkiewicz, The finite element method, 3rd Edition, McGraw-Hill, 1986.

[43] N. Newmark, A method of computation for structural dynamics, ASCE Journal of the Engineering Mechanics Division 85 (1) (1959) 67-94.

[44] O. von Estorff, M. Prabucki, Dynamic response in the time domain by coupled boundary and finite elements, Computational Mechanics 6 (1) (1990) 35-46. doi:10.1007/BF00373797.

URL http://dx.doi .org/10.1007/BF00373797

[45] American Association of State Highway and Transportation Officials, AASHTO LRFD Bridge Design Specifications, 2012.

[46] K. Graff, Wave motion in elastic solids, Oxford University Press, 1975. 